\title{
The bright prospect of biochar
}

\author{
Enthusiasts say that biochar could go a long way towards mitigating climate change and \\ bring with it a host of ancillary benefits. But others fear it could do more harm than good. \\ Kurt Kleiner reports.
}

$J$ im Fournier wants to help save the planet, though in a most unlikely way: by burning biomass. At the forefront of a carbon-sequestration technology that proponents say offers a rare 'win-win-win' environmental opportunity, Fournier's company Biochar Engineering in Golden, Colorado, manufactures machines that turn biomass into charcoal, or biochar.

Spread on soil, biochar can keep $\mathrm{CO}_{2}$ out of the atmosphere while improving soil fertility and boosting productivity. In addition, gases released in the charcoal-making process can be used to make biofuels that are more sustainable than those currently on the market. "Char happens to be the one thing that represents a solution to all of these factors together. It's a unique opportunity," Fournier says.

But while enthusiasts are pushing to have biochar recognized as an official means of offsetting greenhouse gas emissions, others remain cautious. At best we know too little, say critics, and at worst using biochar to sequester carbon could ultimately lead to unintended consequences, including the destruction of virgin forests to make way for plantations.

"Biochar certainly has potential," says David Wardle, a soil scientist at the Swedish University of Agricultural Sciences in Uppsala. "But it's premature to be already including it in carbon accounting. Maybe it really is an answer. But we don't know that yet."

\section{"Biochar certainly has potential. Maybe it really is an answer. But we don't know that yet." \\ David Wardle}

Though the idea of using biochar for climate change mitigation is relatively new, its origins extend back to the preColumbian era, when humans first made terra preta - in Portuguese, dark earth - soils in the central Amazon basin. According to archaeologists, the rich, black and fertile terra preta was created by adding a mixture of bone, manure and charcoal to the otherwise relatively infertile soil over many years. The charcoal - believed to be the key ingredient - is 70 times more concentrated in terra preta than in surrounding soils and is formed by heating biomass in an oxygen-poor or oxygenfree environment. Some of the charcoal in Amazon terra preta soils has persisted for thousands of years, back to when people first started this practice. Its persistence has attracted the attention of research scientists who think that it could be used to lock away carbon for a similarly long time in the future, keeping it out of the atmosphere as a greenhouse gas.

"You can get charcoals that are tens of thousands of years old, or even older," says Chris Turney, a geographer at the University of Exeter and director of the start-up Carbonscape. With headquarters in Blenheim, New Zealand, Carbonscape is developing a unique approach to producing biochar. The company is soon to launch in the United Kingdom. "If you want a very simple method of fixing carbon in a relatively stable form for potentially tens of thousands of years, charcoal is a good way of doing it," Turney says.

\section{TONNES TUCKED AWAY}

The recent surge of interest in biochar as both a commercial venture and an academic challenge was evident at a one-day workshop held last month at the University of Edinburgh and sponsored by the UK Biochar Research Centre. "When I wrote the grant proposal to fund this, I could find only about four or five people in the UK who were interested," says Stuart Haszeldine, the geologist and biochar researcher who organized the event. "Now last week we were turning people away. We had 80 people attend, and we could have had 150."

As a solution to escalating emissions, biochar is certainly promising. Every year, human activity results in the release of somewhere between 8 and 10 billion tonnes of carbon dioxide. Of that, several billion tonnes are soaked up by the oceans and land, leaving around 4.1 billion tonnes in the atmosphere.

That number is dwarfed by the 60.6 billion tonnes of carbon that terrestrial 
plants absorb during photosynthesis every year. A similar amount goes back into the atmosphere through plant respiration. But if a fraction of that carbon could be stored in the soil, it would mitigate climate change to some degree. "Any organic matter that is taken out of the rapid cycle of photosynthesis ... and put instead into a much slower biochar cycle is an effective withdrawal of carbon dioxide from the atmosphere," says Johannes Lehmann, a soil scientist at Cornell University in Ithaca, New York, who has spent years studying terra preta and biochar.

Lehmann and colleagues think that the potential benefits could be huge. Of the more than 60 billion tonnes of carbon taken up annually by photosynthesis, around ten per cent eventually becomes available as agricultural residue such as corn and rice stalks, or forestry residue such as branch and leaf litter, as well as animal waste. If all 6 billion tonnes were put through pyrolysis - the heating process that turns biomass into charcoal -3 billion tonnes of biochar would be produced every year, reducing atmospheric carbon emissions by the same amount ${ }^{1}$. That would offset a substantial proportion of the 4.1 billion tonnes of excess carbon dioxide that accumulates annually in the atmosphere.

And since biochar manufacture has the added benefit of creating liquid fuel as a useful by-product, there's even greater potential for mitigating climate change than from sequestering $\mathrm{CO}_{2}$ alone. According to Lehmann's calculations, a third of a tonne of biofuel could be produced for every tonne of biomass used. If those biofuels replaced fossil fuels - in transport, for example - it would reduce carbon emissions by an additional 1.8 billion tonnes per year.

Tim Lenton, professor of Earth-system science at the University of East Anglia, $\mathrm{UK}$, recently rated biochar as one of the best technological fixes for cooling the planet. According to Lenton's analysis of 17 geoengineering options ${ }^{2}$, biochar has the potential to sequester almost 400 billion tonnes of carbon by 2100 and to lower atmospheric carbon dioxide concentrations by 37 parts per million. Advoctaes, including Lehmann, admit that the real numbers will probably be much smaller. Haszeldine, for instance, says that 1 billion tonnes of carbon sequestered per year by 2030 is a reasonably conservative estimate of biochar's potential. "Even if it's only 500 tonnes of carbon a year, it's useful," says Haszeldine. "If it's a million or a billion tonnes a year, that's significant."

\section{BURNT OFFERING}

Most biochar-making technologies use heat produced by the biomass itself to form the

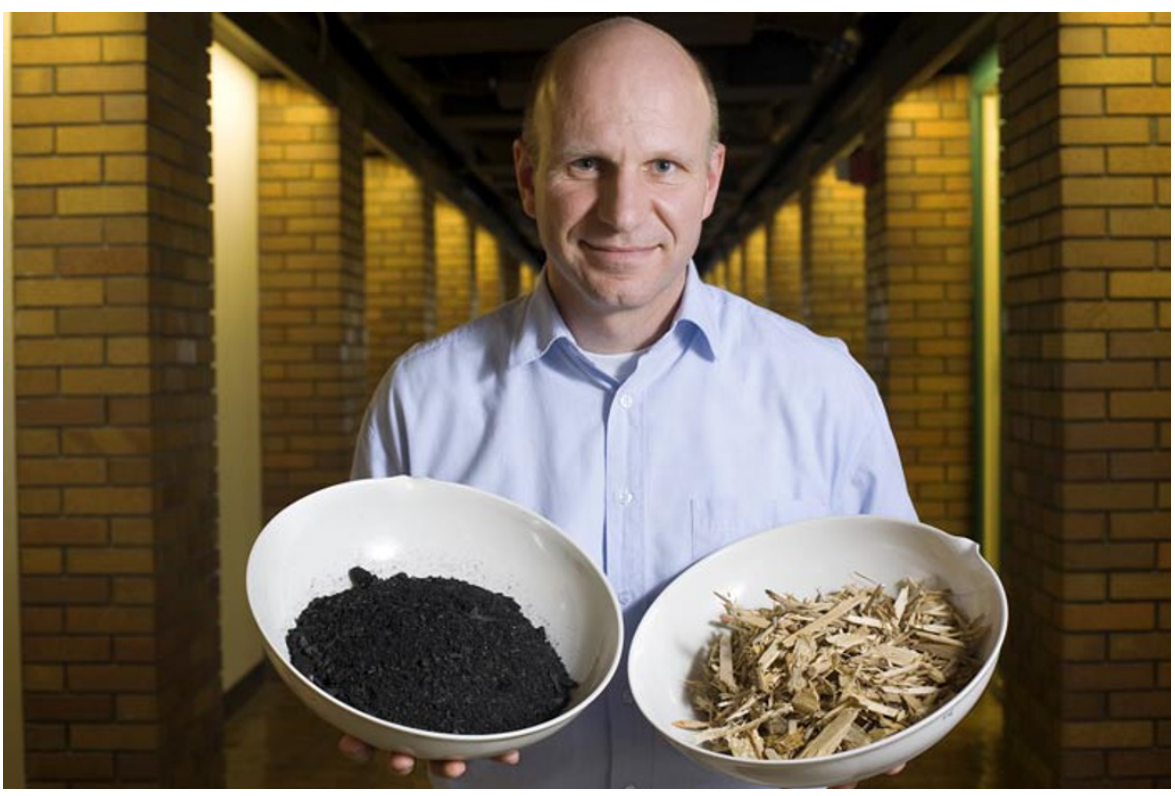

Soil scientist Johannes Lehmann with biochar made from forestry waste.

charcoal. But Turney, the Exeter professor and Carbonscape director, is backing a slightly different approach, one that uses industrial-scale microwaves. He says the idea was inspired by a cooking accident in his teenage years, when he put a potato in the microwave for 40 minutes and it turned into charcoal. Although using microwave technology has the disadvantage of requiring electricity, the process will result in twice as much carbon being stored in the soil as is emitted as greenhouse gas.

\section{"The whole point is to suck up carbon, not to start pillaging native vegetation."}

Chris Turney

A much lower-tech approach is to promote the use of charcoal-making cookstoves to the roughly 2 billion people who rely on wood for fuel. The cook-stoves, produced by a number of companies, use wood or other organic materials as fuel and burn only the gases and oils, leaving charcoal behind. The result is a cleanerburning flame that gives off less smoke, and the leftover biochar can potentially be applied to soil.

Fournier of Biochar Engineering says that he became involved in biochar because of its mitigation potential. But he thinks its value as an addition to the soil will ultimately drive its production. Right now his company manufactures relatively small biochar units for researchers, capable of making 50 kilograms of biochar per hour. He says, however, that the real market will probably be in medium-sized units that can produce 250 to 300 kilograms per hour but are still small enough to be packed into a standard cargo container and shipped anywhere in the world. Fournier expects individual farmers or local entrepreneurs to begin buying the units and using them to make biochar for agricultural purposes, with co-production of energy a secondary benefit. These small operators might decide to forego biofuel production altogether, says Fournier, and concentrate on making biochar. The extra heat generated by the char-making process could be used for warming a building or for industrial processes, however, and possibly for producing electricity.

While charcoal for agricultural use is now selling for about US $\$ 500$ per tonne, that same tonne of charcoal, at current prices, is worth only about US $\$ 50$ if sold for offsetting emissions. Even if the price of carbon offsets rose to US $\$ 100$ per tonne of $\mathrm{CO}_{2}$, that tonne of biochar would still be worth only US $\$ 350$ in offsets, says Fournier. In fact, he says, the economics of biochar will be determined by a combination of its value as a soil additive, as a carbon offset measure and as an energy source.

\section{PRESSURE TO PLANT}

But some worry that once production becomes profitable, pressure will mount to use land specifically for biochar plantations. "The level at which they are promoting this could result in enormous land-use change issues," says Rachel Smolker, a biologist and anti-biochar activist who helped organize a petition in April signed by 143 non- 
profit groups protesting what they called a "charred earth policy". The petition came as a reaction to an effort by 11 African countries and biochar proponents to have the United Nations consider biochar's eligibility as an official means for nations and companies to offset their emissions under international regulations.

"It would require huge areas of land to be turned into plantations," warns Smolker. Carbonscape, for one, has suggested that forests might be planted, harvested for charcoal, and then replanted. For instance, the company says, if the 200 million hectares of forest in the United States that are harvested for timber were instead used for biochar, replanted, and harvested again, each rotation would reduce atmospheric carbon dioxide levels by ten parts per million. Others, such as Lehmann, have proposed replacing winter wheat crops with switchgrass that would be turned into biochar.

Smolker and Almuth Ernsting, who works with Biofuelwatch, a UK environmental organization, are specifically concerned that a market for biochar would encourage the destruction of tropical forests, much as a market for biofuel has encouraged forest destruction for palmoil plantations. Ernsting estimates that sequestering even a relatively modest 1 billion tonnes of carbon a year would require that 500 million hectares of land be devoted to biochar plantations ${ }^{3}$. By comparison, there are an estimated 1.5 billion hectares of tropical forest remaining in the world.

But demand for biochar plantations needn't lead to the destruction of forests, argues Turney. Although he believes it would make the most economic sense to use agricultural and forest waste for biochar, he says that if plantations were needed they could be situated on land that has already been deforested. In fact, he says, biochar production might actually provide an incentive to reforest the estimated 900 million hectares of degraded land worldwide. "The whole point is to suck up carbon, not to start pillaging native vegetation that's already out there," says Turney. Fournier also agrees that destroying forests for biochar plantations would be a perverse effect, but he thinks that international agreements and certification could prevent that from happening.

That isn't Smolker's only concern, though. The hope is that once the carbon is stored in the soil, it will stay there for many thousands of years. But although terra preta shows that's possible, it is not known whether all soils will benefit from biochar application, or even how long

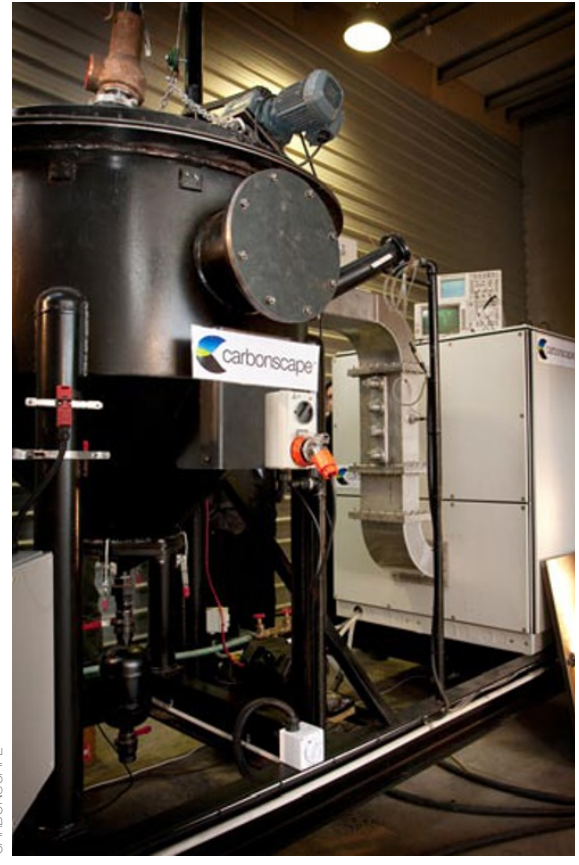

nutrients such as phosphorus, potassium and zinc. But the biochar also seems to help the soil retain some nutrients that would otherwise leach out, as well as helping it to retain water. In addition, biochar might encourage soil microbes that increase crop productivity. And the productivity gains seem to continue to increase even when very high levels of carbon have been added to the soil - up to 140 tonnes per hectare in sandy, weathered soils, and up to about 50 tonnes per hectare on average.

\section{PROCEED WITH CAUTION}

But without more research, says Smolker, it's wrong to assume biochar can be safely applied to soil on a large scale. "I think there's potential that this could backfire and worsen the climate situation," she says. Alan Robock, a climate scientist at Rutgers University, also worries that methods to sequester carbon, including biochar production, could distract attention from the need to reduce emissions. "The people

New Zealand start-up Carbonscape is using industrialscale microwaves to turn biomass into biochar.

modern manufactured char will persist. "You can't assume that modern biochar behaves like terra preta," says Smolker. Soil scientist David Wardle reported in Science last year that, in Swedish forests at least, charcoal may cause carbon to disappear from the soil much more quickly than expected ${ }^{4}$. Wardle and his team left mesh bags containing either humus, charcoal or a mixture of both on the forest floor and recorded how much mass was lost from each over a ten-year period. They found that the mixtures of humus and charcoal lost more mass than the controls of humus and charcoal alone. Wardle thinks that the charcoal promoted microbial breakdown of the humus, accelerating the release of $\mathrm{CO}_{2}$ back into the atmosphere. It's also possible that some microbes could degrade biochar directly. Although the black carbon that makes up the bulk of biochar is thought to be biologically unavailable to most microbes, research suggests that some microbes might be able to metabolize it. If so, it would be less stable in soil than currently thought ${ }^{5}$.

Another outstanding issue is to what extent modern-day biochar application will fulfil the promise of terra preta in improving soil fertility. Research by Lehmann ${ }^{6}$ suggests that in most cases the addition of charcoal improves soil productivity, and although the reasons for the increased fertility still aren't entirely understood, several things seem to be going on. First, the biochar itself contains some who created the problem like the idea. They can keep using the atmosphere as a sewer and let other people clean up the mess," he says.

Most biochar researchers agree that the technology needs more study and that the most important thing is to reduce emissions in the first place. "Biochar is not a silver bullet for sequestration," Lehmann says. "We cannot continue the emissions that we generate today and anticipate that any technology or combination of technologies could compensate." Nevertheless, it's possible that biochar could help mitigate those emissions, he says.

"Part of what our group will be trying to do is to contribute to that work, and monitor and review where all this has got to," Haszeldine says. "We want to make sure we're not making a giant mistake."

Published online: 21 May 2009

doi:10.1038/climate.2009.48

References

1. Amonette, J. et al. in American Geophysical Union Fall Meeting 2007, abstract U42A-06; http://tiny.cc/biochar 1

2. Lenton, T. M. \& Vaughan, N. E. Atmos. Chem. Phys. Discuss. 9, 2559-2608 (2009).

3. Ernsting, A. \& Smolker, R. Biochar for Climate Change Mitigation: Fact or Fiction? (Biofuelwatch, 2009); http://tiny.cc/biochar

4. Wardle, D. A. Science 320, 629 (2008).

5. Hamer, U., Marschner, B., Brodowski, S. \& Amelung, W. Org. Geochem. 35, 823-830 (2004).

6. Lehmann, J. \& Rondon, M. in Biological Approaches to Sustainable Soil Systems (eds Uphoff, N. et al.) 517-530 (CRC Press, 2006).

Kurt Kleiner is a freelance science writer based in Toronto. 